\title{
25 Research Square \\ Study on the influence of stress wave disturbance on ultra-low friction effect of broken blocks
}

\author{
liping $\mathrm{Li}$ \\ Liaoning Technical University https://orcid.org/0000-0001-9294-6941 \\ haitao Zhang ( $\nabla$ zhanghaitao422@163.com ) \\ Liaoning Technical University https://orcid.org/0000-0002-3659-5953 \\ yishan Pan \\ Liaoning University \\ xiangyu Ju \\ Liaoning Technical University \\ lei Tang \\ Liaoning Technical University \\ minghui Li \\ Liaoning Technical University
}

\section{Research}

Keywords: Rock burst, Block rock mass, ultra-low friction effect, stress wave disturbance, horizontal displacement

Posted Date: September 17th, 2021

DOI: https://doi.org/10.21203/rs.3.rs-895689/v1

License: (1) (1) This work is licensed under a Creative Commons Attribution 4.0 International License.

Read Full License 


\title{
Study on the influence of stress wave disturbance on ultra-low friction effect of broken blocks
}

\author{
Liping $\mathrm{LI}^{\mathrm{a}}$, Haitao ZHANG ${ }^{\mathrm{a}}$, Yishan PAN ${ }^{\mathrm{b}}$, Xiangyu JU' ${ }^{\mathrm{a}}$, Lei TANG ${ }^{\mathrm{a}}$, Minghui $\mathrm{LI}^{\mathrm{a}}$ \\ (a. School of Mechanics and Engineering, Liaoning Technical University, Fuxin 123000, China; \\ b. School of Physics, Liaoning University, Shenyang, Liaoning 110036, China)
}

\begin{abstract}
Correspondence information: Haitao ZHANG, Collage of Mechanics Engineering, Liaoning Technical University, No. 47, Zhonghua Road, Xihe District, Fuxin City, Liaoning

Province,China,zhanghaitao422@163.com
\end{abstract}

\begin{abstract}
With the increase of mine mining depth, deep rock mass tends to be broken into block medium. The roof-rock layer-floor can be regarded as block system fractured rock mass. Under the condition of high ground stress and mining disturbance, the ultra-low friction effect of block system fractured rock mass is easy to occur, and then induce rock burst and other disasters. Taking the block rock mass as the research object, the self-developed ultra-low friction test system is used to carry out the experimental research on the ultra-low friction effect of the broken block under the condition of stress wave disturbance. Taking the horizontal displacement of the working block as the characteristic parameter reflecting the ultra-low friction effect, by changing the stress wave disturbance frequency and amplitude, the characteristic law of the horizontal displacement, acceleration and energy of the working block during the occurrence of the ultra-low friction effect is analyzed. The research results show that the stress wave disturbance frequency is related to the generation of ultra-low friction of the broken block. The disturbance frequency of the stress wave is within $1 \sim 3 \mathrm{~Hz}$, and the maximum acceleration and horizontal displacement of different broken degree blocks increase significantly. This frequency range is prone to ultra-low friction effect. The greater the intensity of the stress wave disturbance, the higher the degree of block fragmentation, and the more likely to have ultra-low friction effects between the blocks. The greater the intensity of the horizontal impact load, the higher the degree of rock mass fragmentation, the easier it is for ultra-low friction effects to occur. Stress wave disturbance and horizontal impact are the main reasons for the sliding instability of broken blocks. When the dominant frequency of the kinetic energy of the broken block is within 20 $\mathrm{Hz}$, the ultra-low friction effect is more likely to occur.
\end{abstract}

Keywords: Keyword 1. Rock burst; Keyword 2. Block rock mass; Keyword 3. ultra-low friction effect; Keyword 4. stress wave disturbance; Keyword 5. horizontal displacement

\section{Introduction}

Under the action of long-term high ground stress, the deep rock mass is usually an intermittent structure with joints and fissures. Under the repeated disturbance of vertical disturbance and horizontal impact caused by roof fracture, mechanical vibration, etc., the rock mass around the stope and roadway constantly vibrates, deforms and breaks, forming a block-broken structure. In particular, the rock layers gradually changed from intermittent to loose and 
broken. When the stress wave disturbance and the load effect reach the critical conditions, the vibration makes the blocky broken rock mass receive the positive pressure as a tensile force. The blocky rock mass is prone to sudden interlayer slippage under the surrounding load, which instantly causes the roof, rock strata, and bottom plate to slip. The slip velocity along the contact structure surface increases nonlinearly, and the frictional resistance is weakened or even extremely weak, and then the ultra-low friction effect of the block fractured rock mass occurs.

The ultra-low friction effect of rock mass was first discovered and proposed by Russian scholars Kurlenya M V and Oparin V N in 1995. They believe that when the dynamic impulse acts on the rock mass, due to the vibration between the rock masses, the relative compaction between the rock masses changes with time. At certain moments when the rock masses are relatively loose, the frictional resistance between the rock masses will be greatly reduced (even Up to several times), with friction "disappearing" effect (Kurlenya M V et al.1996; Kurlenya M V et al.1999; Oparin V N et al.2001). The low-friction shear effect is the reason for the high energy release of earthquakes and rock fractures in deep underground mines (B.G. Tarasov and Randolph 2007). The phenomenon of ultra-low friction exists in the block structure of rock mass, and the ultra-low friction effect of the rock mass is a key scientific problem in deep mining (QIAN Qi-hu 2004). The large increase in stress drop means that small disturbances in lateral stress may cause the appearance of "low friction" (CUI Yong-quan et al.2005). Wang Hong-liang et al. (2006) established a dynamic model of block rock mass through the description and summary of the ultra-low friction experimental phenomenon, and preliminarily revealed the internal mechanism of the ultra-low friction phenomenon through the comparison of numerical analysis and experimental data (Wang and $\mathrm{Ge}$ 2007). Wu Hao et al. (2008) established a one-dimensional dynamic model of the deep block system rock mass and obtained an analytical expression for the horizontal displacement of the working block (Wu and Fang 2009; Wu Hao et al.2009; Wu and Fang 2010). Xu Qiong-ping et al. (2009) used the deep rock dynamic characteristics multifunctional test system to test the dynamic characteristics of block rock under vertical impact load and horizontal tension, and established the functions of impact energy and characteristic friction force, impact energy and friction reduction coefficient relationship. Based on the discontinuous self-balanced in-situ stress hierarchical block system structure theory of deep rock masses, Wang Kai-xing et al. (2016) studied the energy transformation law between the rock block and its surrounding weak medium in the process of pendulum wave propagation, and analyzed the energy transfer law in the self-stress block rock mass. Liu Dong-qiao et al. (2018) carried out static and dynamic load joint action test, simulated the process of rock burst damage induced by roadway, analyzed the fragmentation state and shape, and proposed a test method to determine whether rock burst is induced by dynamic load. Li Li-ping et al. (2019) proposed a new concept of ultra-low friction rock burst, established a block model of ultra-low friction rock burst, and derived the expression of normal dynamic load on the interface between lump coal and rock mass with time. The FLAC ${ }^{3 \mathrm{D}}$ numerical software is used to apply the ultra-low friction numerical simulation of the combined action of vertical impact and horizontal static force, vertical impact and horizontal impact to the granite block. The residual displacement and normal force evolution law of the working block in the model is obtained. The vertical and horizontal stress distribution characteristics of the block model (Lv Jia-qing 2015). Li Jie et al. (2018) used the self-developed test system of dynamic mechanical properties of block rock mass to carry out physical simulation tests of rock block slip induced by impact disturbance, and obtained the key mechanical mechanisms and laws of irreversible rock displacement and dynamic slip instability induced by impact disturbance. Jiang Hai-ming et al. (2019) simplified the block system rock mass into an equivalent mass-viscoelastic model, introduced a weakening model of rock friction slip rate, and finally obtained a rock mass slip instability calculation model. Through calculation and analysis of the influence of the characteristics of the block system rock mass and the external load characteristics on the low friction effect between the rock blocks. 
Zhao An-ping et al. (2018) established a one-dimensional analysis model of jointed rock mass and carried out dimensional analysis to discuss the influence of joint characteristics on the law of stress wave propagation.

Based on the above research results, in the theoretical models of block rock mass established by domestic and foreign scholars, only the dynamic response under vertical impact load and horizontal static force is analyzed. On this basis, there is a lack of further analysis on the influence of parameters such as the degree of block fragmentation and the disturbance frequency and amplitude of stress wave on the ultra-low friction effect of block rock mass. In this paper, on the basis of the direction of research scholars, the ultra-low friction effect was designed and developed to load test device, in under the action of stress wave disturbance crushing block of ultra-low friction effect test, to work for the parameter block horizontal displacement and horizontal acceleration, the study of the stress wave disturbance frequency and intensity of disturbance of the broken block of ultra-low friction effect. The obtained research results are compared with the related results of predecessors, and provide a scientific basis for the prediction and prevention of disasters caused by the ultra-low friction effect.

\section{Establishment of theoretical model of ultra-low friction effect of block rock mass}

In the process of establishing the theoretical model of the ultra-low friction effect, springs or spring damping are often used to simulate the mechanical characteristics of the weak interlayer, and the overall model is established by connecting the mass points. In recent years, some mechanical models have been put forward in the study of block system rock mass dynamics (Wu and Fang 2009; Wu Hao et al.2009; Wu and Fang 2010), which provide a theoretical basis for studying the ultra-low friction effect of block system broken rock mass.

\subsection{Model establishment}

The deep rock mass is divided by geological structures such as fissures and joints. The mechanism of the ultra-low friction effect is closely related to the dynamic deformation characteristics of the block interface and the stability of the block system. To study the deformation characteristics of deep block media, we must first reveal the normal and tangential dynamic characteristics of the block interface. Therefore, on the basis of previous research, the block is regarded as a rigid body, and the theoretical model of ultra-low friction effect as shown in Figure 1 is established. In Figure 1, the size of the block is the same, and the mass is $m_{i}$, vertical impact $P_{v}(t)=P_{v} \sin \omega_{v} t$, Axial pressure $\gamma H$, Acting on the surface of block 1. Springs and dampers are set between the blocks to describe the energy transfer and retardation of the weak connecting medium between the blocks. The stiffness coefficient is $k_{i}$ and the damping coefficient is $c_{i}$. The movement of the block consists of two stages. The first stage is forced vibration under the action of a vertical impact, and the second stage is the free vibration of the block starting from the moment $t_{0}$ with the state of that moment as the initial condition. 


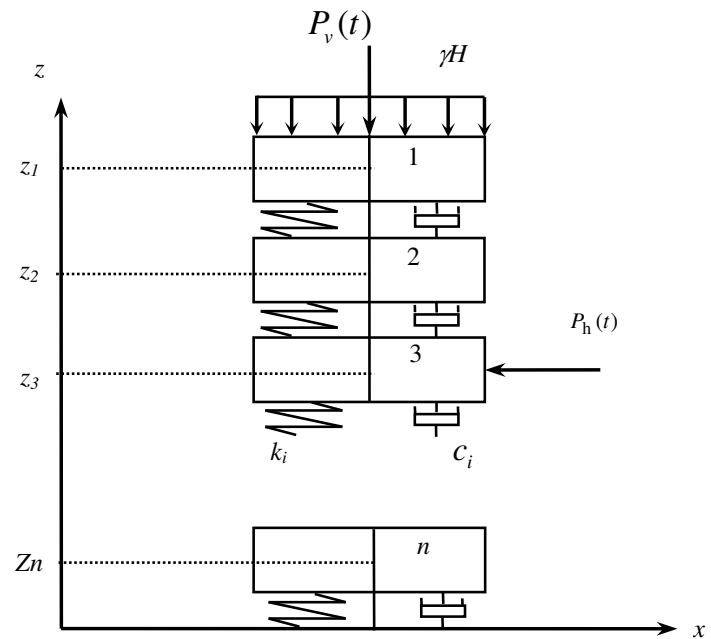

Fig 1 Theoretical model of ultra-low friction effect

The block system is composed of $\mathrm{n}$ blocks stacked vertically, suppose the vertical upward is the positive direction, and the position 1 from the center of the bottom surface of the $n$-th block is the coordinate origin, The equation of motion in the vertical direction are given by:

$$
\left.\begin{array}{c}
m \ddot{z}_{1}+k_{1}\left(z_{1}-z_{2}-l\right)+c_{1}\left(\dot{z}_{1}-\dot{z}_{2}\right)=m g+P_{v} \sin (\omega t)+F_{v} \\
m \ddot{z}_{2}+k_{2}\left(z_{2}-z_{3}-l\right)+c_{2}\left(\dot{z}_{2}-\dot{z}_{3}\right)-k_{1}\left(z_{1}-z_{2}-l\right)-c_{1}\left(\dot{z}_{1}-\dot{z}_{2}\right)=m g \\
\cdots \cdots \\
m \ddot{z}_{i}+k_{i}\left(z_{i}-z_{i+1}-l\right)+c_{i}\left(\dot{z}_{i}-\dot{z}_{i+1}\right)-k_{(i-1)}\left(z_{i-1}-z_{i}-l\right)-c_{(i-1)}\left(\dot{z}_{i-1}-\dot{z}_{i}\right)=m g \\
\cdots \cdots \\
m \ddot{z}_{n}+k_{\mathrm{n}}\left(z_{n}-l\right)+c_{n} \dot{z}_{n}-k_{(n-1)}\left(z_{n-1}-z_{n}-l\right)-c_{(n-1)}\left(\dot{z}_{n-1}-\dot{z}_{n}\right)=m g
\end{array}\right\}
$$

Where $m_{i}$-Block mass; $z_{i}$-Ordinate of block $i ; l$-Free length of spring; $g$-Acceleration of gravity; $F_{v}-$ The resultant force of ground stress in the vertical direction of the model.

Simplify the above formula into a matrix form, and get:

$$
M \ddot{\mathbf{z}}+\mathbf{C} \dot{\mathbf{z}}+\mathbf{K z}=\mathbf{F}(t)+\mathbf{b}
$$

Where

$$
\begin{aligned}
& \boldsymbol{M}=\left(\begin{array}{ccccccc}
m_{1} & 0 & 0 & 0 & \cdots & 0 & 0 \\
0 & m_{2} & 0 & 0 & \cdots & 0 & 0 \\
0 & 0 & m_{3} & 0 & \cdots & 0 & 0 \\
\cdots & \cdots & \cdots & \cdots & \cdots & \cdots & \cdots \\
0 & 0 & 0 & 0 & \cdots & m_{(n-1)} & 0 \\
0 & 0 & 0 & 0 & \cdots & 0 & m_{\mathrm{n}}
\end{array}\right) \quad \boldsymbol{K}=\left(\begin{array}{ccccccccc}
-k_{1} & k_{1} & 0 & 0 & \cdots & 0 & 0 \\
-k_{1} & k_{1}+\mathrm{k}_{2} & -k_{2} & 0 & \cdots & 0 & 0 \\
0 & -k_{2} & k_{2}+\mathrm{k}_{3} & -k_{3} & \cdots & 0 & 0 \\
\cdots & \cdots & \cdots & \cdots & \cdots & \cdots & \cdots \\
0 & 0 & 0 & 0 & \cdots & k_{(n-2)}+\mathrm{k}_{(n-1)} & -k_{(n-1)} \\
0 & 0 & 0 & 0 & \cdots & -k_{(n-1)} & k_{(n-1)}+k_{n}
\end{array}\right) \\
& C=\left(\begin{array}{ccccccccc}
c_{1} & -c_{1} & 0 & 0 & \cdots & 0 & 0 \\
-c_{1} & c_{1}+c_{2} & -c_{2} & 0 & \cdots & 0 & 0 \\
0 & -c_{2} & c_{2}+c_{3} & -c_{3} & \cdots & 0 & 0 \\
\cdots & \cdots & \cdots & \cdots & \cdots & \cdots & \cdots \\
0 & 0 & 0 & 0 & \cdots & c_{(n-2)}+c_{(n-1)} & -c_{(n-1)} \\
0 & 0 & 0 & 0 & \cdots & -c_{(n-1)} & c_{(n-1)}+c_{n}
\end{array}\right)
\end{aligned}
$$




$$
\boldsymbol{F}(t)=P_{\mathrm{v}}\left(\begin{array}{c}
\sin \omega t \\
0 \\
\ldots \\
0
\end{array}\right), \quad \boldsymbol{z}=\left(\begin{array}{c}
z_{1} \\
z_{2} \\
\vdots \\
z_{n}
\end{array}\right), \quad \boldsymbol{b}=\left\{\begin{array}{c}
m g+k_{1} l+F_{\mathrm{v}} \\
m g+\left(k_{2}-k_{1}\right) l \\
\ldots \\
m g+\left(k_{n}-k_{(n-1)}\right) l
\end{array}\right\}
$$

Suppose the third block is the working block, which is acted on by the horizontal force $P_{h}(t)$, and the equation of motion in the horizontal direction is:

$$
m \ddot{u}=P_{h}(t)-\mu_{d} N(t)
$$

Where $u$-Block horizontal movement displacement, $\mathrm{m} ; \mu_{d}$-Dynamic friction coefficient between blocks; $N(t)$ - Normal force on the block, $\mathrm{N}$.

Set $\mathrm{z}=\mathrm{z}^{0}+\mathrm{y}$, the vertical balance position has:

$$
\mathbf{K} z^{0}=\mathbf{b}
$$

Solve the initial coordinates of each block in the $\mathrm{z}$-axis direction as:

$$
z_{i}^{0}=(n-i+1) l+\sum_{j=i}^{n}\left(\frac{j m g+F_{v}}{k_{j}}\right) \quad(i=1,2, \cdots, \mathrm{n})
$$

Substituting $\mathrm{z}=\mathrm{z}^{0}+\mathrm{y}, \mathbf{K} z^{0}=\mathbf{b}$ into the matrix equation, we get:

$$
\boldsymbol{M} \ddot{\mathrm{y}}+\boldsymbol{C} \dot{y}+\boldsymbol{K y}=\boldsymbol{F}(t)
$$

Set $k_{1}=k_{2}=\cdots=k_{n}, c_{1}=c_{2}=\cdots=c_{\mathrm{n}}, m_{1}=m_{2}=\cdots=m_{\mathrm{n}}$, the approximate solution of the block acceleration in the model is:

$$
\ddot{z}_{i}=\frac{2 P_{\mathrm{v}} l^{2}}{\mathrm{~m} \omega_{\mathrm{v}}(\gamma t)^{2 / 3}} \sqrt{\frac{k}{m}} \frac{1}{\pi} \int_{0}^{\infty} \sin \left(\zeta z+z^{3} / 3\right) \mathrm{e}^{-\mu z^{2}} z \mathrm{~d} z
$$

Where $\gamma=\frac{c_{1} l^{2}}{8}\left(1+\frac{3 c^{2}}{m k}\right) ; \quad \zeta=\frac{i l-c_{1} t}{(\gamma t)^{1 / 3}} ; \quad \mu=\frac{\alpha t}{(\gamma t)^{2 / 3}} ; \quad \alpha=\frac{c l^{2}}{m} ; \quad c_{1}=l \sqrt{\frac{k}{m}} ; l$-Free length of spring, $\mathrm{m} ;$

$k_{i}$-Spring stiffness coefficient; $m_{i}$-Block mass, kg.

\subsection{Comparative analysis of test theory}

Since the correctness of the above theoretical model has been verified ( $\mathrm{Li} \mathrm{Li}$-ping et al. 2019). In order to study the effect law of stress wave disturbance on ultra-low friction effect of fractured rock mass under axial compression and facilitate comparative analysis, ultra-low friction tests under the combined action of axial compression and stress wave disturbance were conducted. The size of the block is $100 \mathrm{~mm} \times 100 \mathrm{~mm} \times 100 \mathrm{~mm}$, and the mass of the block is $2.56 \mathrm{~kg}$. The test model consists of five rock blocks stacked in the vertical direction without weak interlayers. A 4MPa axial pressure is applied to block 1 to simulate the pressure effect of the overlying rock layer, and the stress wave disturbance function is applied, and the stress wave disturbance amplitude is applied, it is $40 \mathrm{kN}$, and the disturbance frequency is $1 \mathrm{~Hz}, 3 \mathrm{~Hz}, 5 \mathrm{~Hz}, 10 \mathrm{~Hz}, 20 \mathrm{~Hz}$. Acceleration sensor (attached to the center of the block), the data acquisition instrument is used to collect test data. 


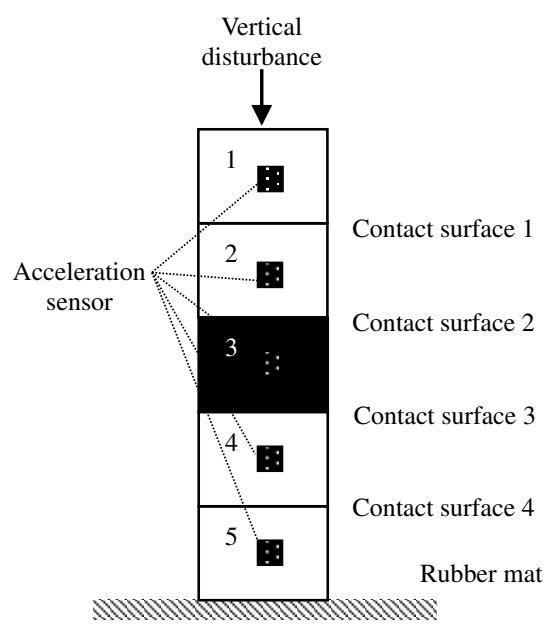

Fig.2 Schematic diagram of verification test device

The calculation in the theoretical formula is consistent with the test parameters: $P_{v}=40 \mathrm{kN}, \omega_{v}=31.42(f=5 \mathrm{~Hz})$ $c=60 \mathrm{~N} \cdot \mathrm{s} / \mathrm{m}, k=4.0 \times 10^{6} \mathrm{~N} / \mathrm{m}, l=0.005 \mathrm{~m}, m_{i}=2.56 \mathrm{~kg}$. The working block is the third block and takes its acceleration as a parameter, sorts out the test data, and compares the result with the acceleration derived from the theoretical model, as shown in Figure 3.

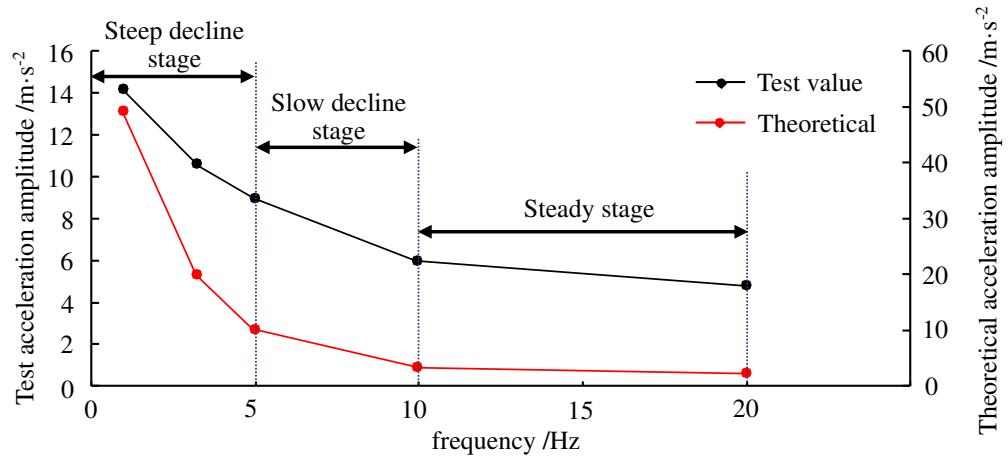

Fig. 3 Curve of maximum acceleration with disturbance frequency

It can be seen from Figure 3: The maximum acceleration of the test block and the theoretical block both decrease with the increase of frequency. The acceleration amplitude of the working block can be divided into three stages, which are the steep decline stage, the slow decline stage and the steady stage. When the perturbation frequency is in the range of $1 \sim 5 \mathrm{~Hz}$, the amplitude of acceleration change is larger, indicating that low-frequency perturbation has a significant impact on the movement of the block. When the disturbance frequency is $1 \mathrm{~Hz}$, a maximum acceleration of respectively $14.13 \mathrm{~m} / \mathrm{s}^{2}$ and $49.52 \mathrm{~m} / \mathrm{s}^{2}$. With the increase of the disturbance frequency, the change trend of the block acceleration amplitude slows down and stabilizes. Due to the difference between the theoretical model and the experimental conditions, the maximum acceleration is different, but the change trend is consistent with the frequency of the stress wave disturbance. Therefore, the rationality of this experiment is verified.

\section{Ultra-low friction test of broken block}

\subsection{Ultra-low friction test system}

The equipment used in the test can realize the three-dimensional stress loading of the broken rock mass, and better simulate the real stress condition of the broken rock mass when the ultra-low friction rock burst occurs. The loading equipment is composed of four main parts: axial pressure loading mechanism, confining pressure loading 
mechanism, impact loading mechanism and disturbance loading mechanism. This design mainly adopts hydraulic transmission and control system. The model size of the test block can be adjusted according to different test requirements. The length range is $0 \sim 200 \mathrm{~mm}$, the width range is $0 \sim 200 \mathrm{~mm}$, and the height range is $0 \sim 600 \mathrm{~mm}$. Confining pressure can be applied to the front and back of the test body, in the range of $0 \sim 30 \mathrm{MPa}$; horizontal impact is applied to the left side, in the range of $0 \sim 30 \mathrm{MPa}$. The axial pressure and vertical disturbance can be applied in the vertical direction at the same time, the axial pressure range is $0 \sim 30 \mathrm{MPa}$; the vertical disturbance range is $0 \sim 3 \mathrm{MPa}$, and the frequency can be adjusted within $0 \sim 50 \mathrm{~Hz}$, as shown in Figure 4 . The horizontal displacement of the block is measured by the Panasonic mini laser sensor.

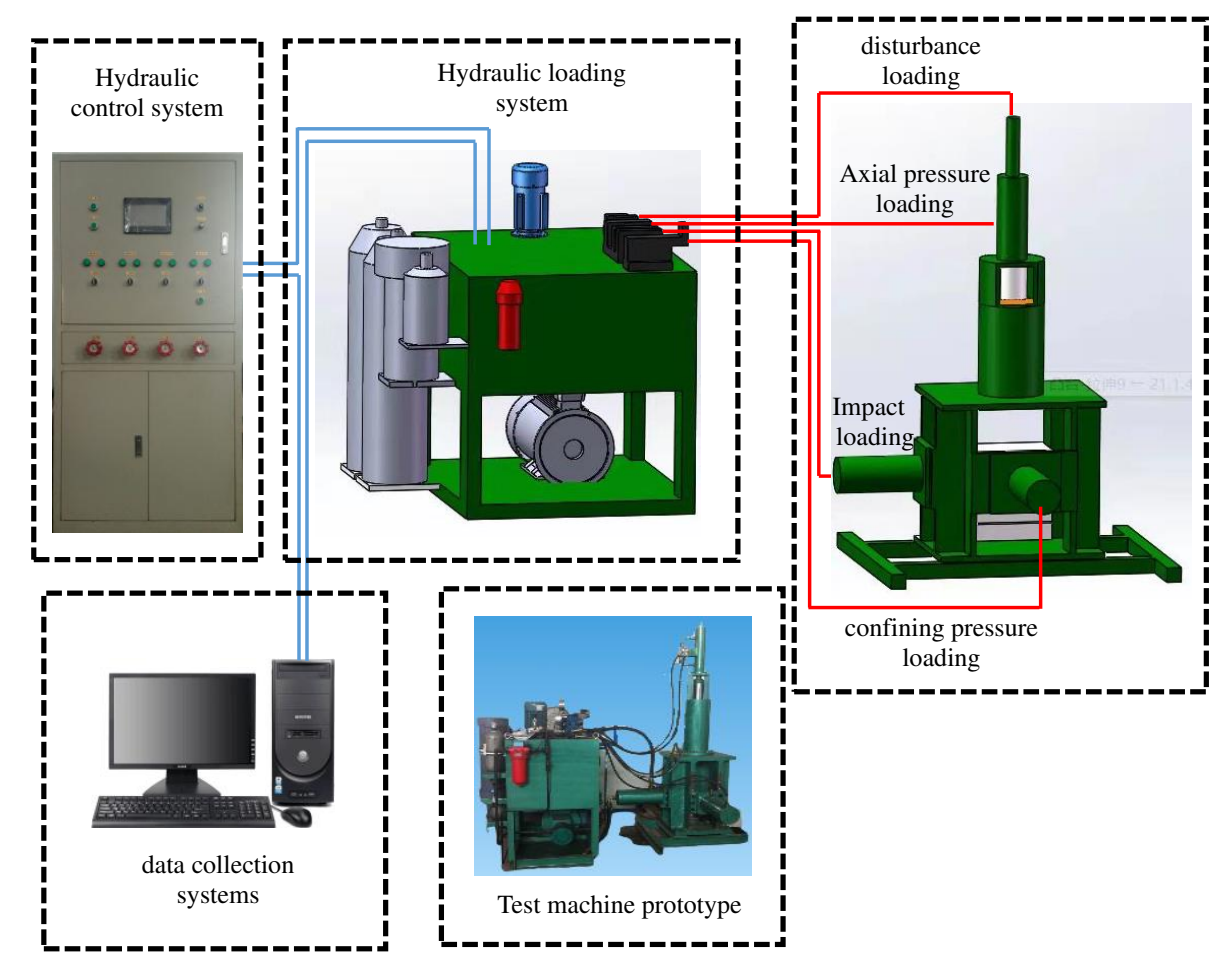

(The red solid line in the picture is the pipe connection, and the blue solid line is the wire)

Fig.4 Ultra-low friction test system

\subsection{Preparation of test pieces}

Red sandstone has uniform grain size and is widespread underground. Therefore, the rock sample used in the test was selected as red sandstone. In order to make the test results comparable, all samples are required to be taken from the same sandstone with good integrity and homogeneity. The samples used in the test are all processed into cylinders with a diameter of $50 \mathrm{~mm}$ and a height of $100 \mathrm{~mm}$, and the samples are polished to ensure that the parallelism of the surfaces at both ends is within $0.05 \mathrm{~mm}$ and the surface flatness is within $0.02 \mathrm{~mm}$. The uniaxial compression test of the rock sample is carried out in the mechanics laboratory. All the tests adopt the displacement-controlled loading method, and the loading rate is required to be constant at $0.15 \mathrm{~mm} / \mathrm{min}$. 

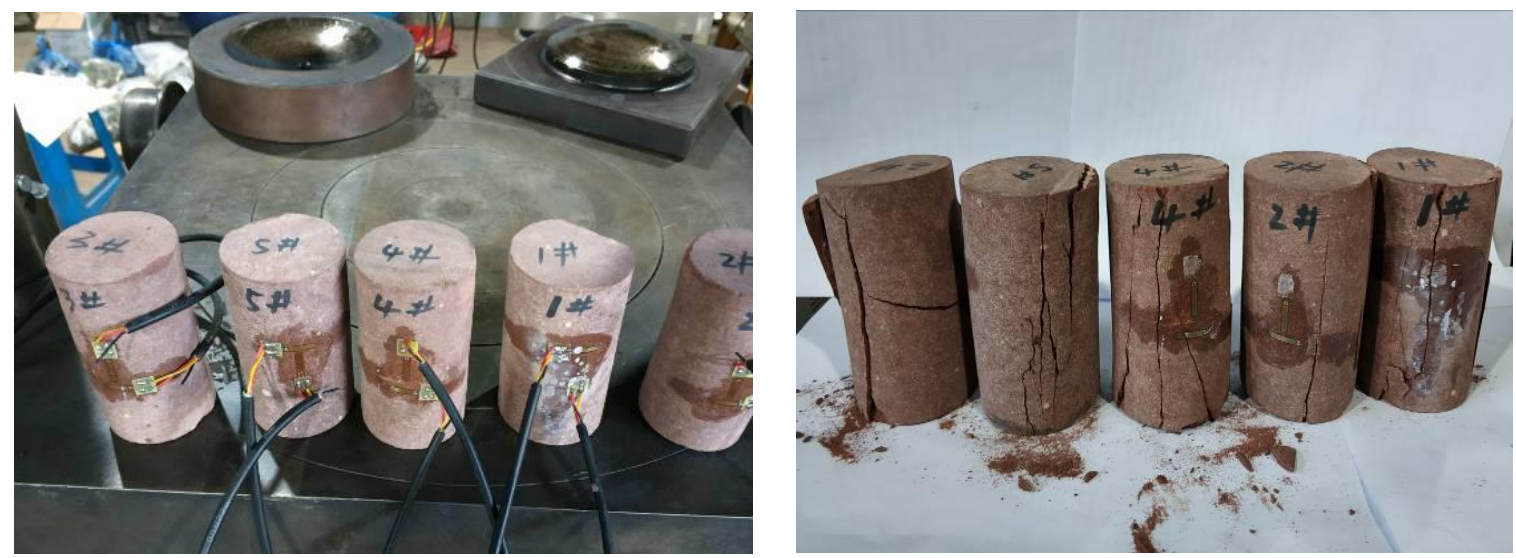

Fig 5 Standard rock sample and broken state after test

Tab 1 Physical and mechanical parameters of coal

\begin{tabular}{cccc}
\hline $\begin{array}{c}\text { Rock sample } \\
\text { number }\end{array}$ & $\begin{array}{c}\text { Elastic } \\
\text { Modulus }\end{array}$ & $\begin{array}{c}\text { Poisson's } \\
\text { ratio }\end{array}$ & $\begin{array}{c}\text { Uniaxial compressive } \\
\text { strength }\end{array}$ \\
& $\mathrm{E} / \mathrm{GPa}$ & $\mu$ & $\sigma_{c} / \mathrm{MPa}$ \\
\hline 1 & 4.92 & 0.221 & 38.35 \\
2 & 6.29 & 0.263 & 44.19 \\
4 & 5.35 & 0.282 & 44.60 \\
5 & 4.99 & 0.191 & 38.44 \\
average value & 5.39 & 0.239 & 41.39 \\
\hline
\end{tabular}

\subsection{Test plan}

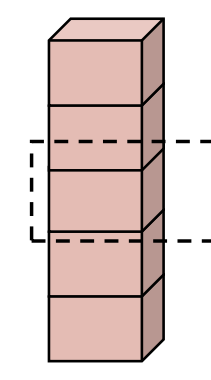

Intact sandstone block

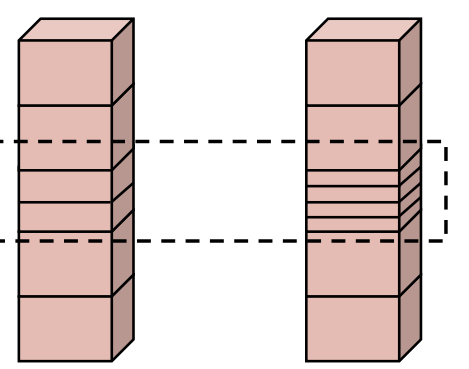

Two sandstone rock blocks
Four sandstone rock blocks

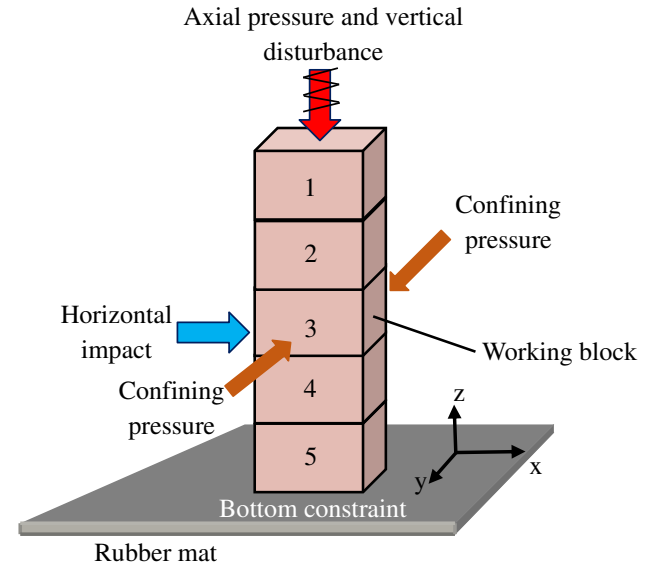

Rubber mat

Fig 6 Block placement and loading model diagram

The test adopts a self-developed ultra-low friction effect test device to study the effects of stress wave disturbance frequency and disturbance intensity on the ultra-low friction effect of broken blocks. The stress wave disturbance intensity is characterized by the disturbance amplitude of the test device. According to the research of Wu Hao et al. (2010), each group in this experiment uses 4 complete blocks of $100 \mathrm{~mm} \times 100 \mathrm{~mm} \times 100 \mathrm{~mm}$ and a working block in the middle position. Set the working block to number 3. In the three sets of tests, the working blocks were one $100 \mathrm{~mm} \times 100 \mathrm{~mm} \times 100 \mathrm{~mm}$ sandstone block, two $100 \mathrm{~mm} \times 100 \mathrm{~mm} \times 50 \mathrm{~mm}$ sandstone blocks, and four $100 \mathrm{~mm} \times 100 \mathrm{~mm} \times 25 \mathrm{~mm}$ sandstone blocks. Axial pressure and disturbance are applied to the uppermost block in 
the vertical direction. The stress wave disturbance form is a sine wave. This paper does not consider the delay time effect, and applies a horizontal impact to the rock block at $t_{0}$.

The specific experimental steps are as follows:

(1) Put the Intact sandstone block in the testing machine from top to bottom in the vertical direction, apply 4 MPa axial pressure in the vertical direction, and set the confining pressure to $15 \mathrm{MPa}$.

(2) The stress wave disturbance is applied in the vertical direction, the initial stress wave disturbance amplitude is $0.3 \mathrm{MPa}$, and the vibration frequency is $1 \mathrm{~Hz}$.

(3) A horizontal impact is applied to the No. 3 working block, and the horizontal displacement of the working block is measured by the optical fiber non-contact displacement sensor, the acceleration is measured by the acceleration sensor.

(4) Change the stress wave disturbance frequency, disturbance amplitude and horizontal impact in turn, and carry out the test.

(5) Replace the working block with two sandstone rock blocks and four sandstone rock blocks, repeat the steps (1) (2) (3) (4) respectively, and record the data.

\section{Analysis of the influence of stress wave disturbance}

\subsection{Stress wave disturbance frequency influence analysis}

(1) Analysis of the influence of the horizontal displacement of the broken block

As the frequency of stress wave disturbance increases, the horizontal displacements of blocks of different fragmentation levels all show the fluctuation characteristics of increasing first and then decreasing. When the stress wave disturbance frequency is $1 \sim 3 \mathrm{~Hz}$, there is a high displacement area of the working block. Under the same level of impact and stress wave frequency, the horizontal displacement of the four sandstone rock blocks is the largest, followed by the two sandstone rock blocks, and the intact sandstone block is the last.

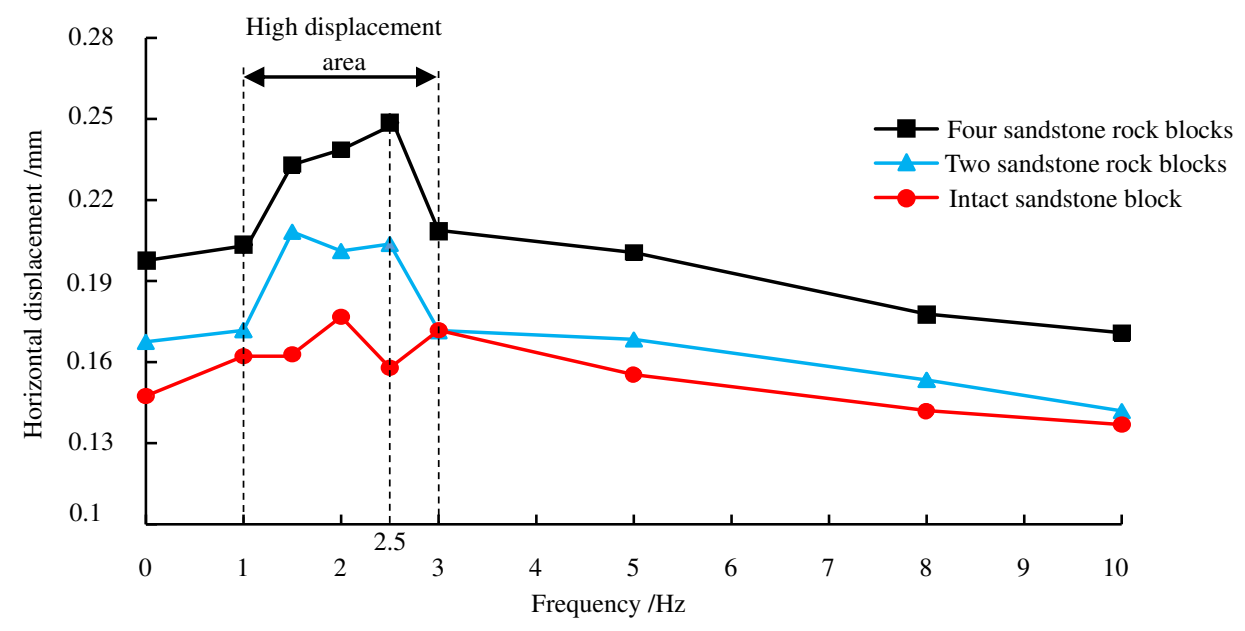

(a) The relationship between the horizontal displacement of the broken block and the disturbance frequency under a horizontal impact of $1.5 \mathrm{MPa}$ 


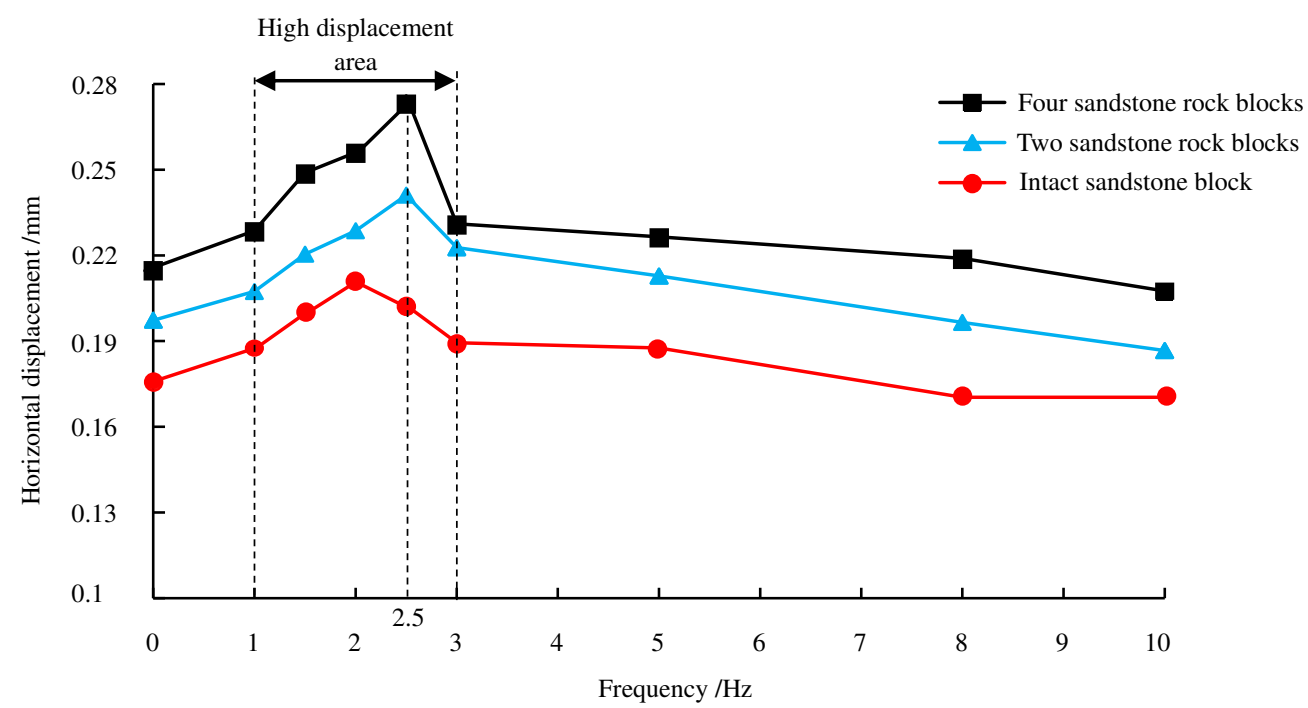

(b) The relationship between the horizontal displacement of the broken block and the disturbance frequency under a horizontal impact of $2.5 \mathrm{MPa}$

Fig. 7 Relationship between horizontal displacement of broken block and frequency of stress wave disturbance

As shown in Figure 7, as the frequency of stress wave disturbance increases, blocks with different fragmentation levels have high displacement areas. Under the same disturbance frequency, the residual displacement of the four sandstone rock blocks is the largest, followed by the two sandstone rock blocks, and finally the intact sandstone block. In the high displacement area, when the frequency is $2.5 \mathrm{~Hz}$, the horizontal displacement of the block is the largest, indicating that the ultra-low friction effect of the block is the strongest at this frequency during the entire dynamic disturbance process. Taking the horizontal impact of $1.5 \mathrm{MPa}$ as an example, when the disturbance frequency is increased from $1 \mathrm{~Hz}$ to $1.5 \mathrm{~Hz}, 2 \mathrm{~Hz}, 2.5 \mathrm{~Hz}, 3 \mathrm{~Hz}$, the residual displacement of the four sandstone rock blocks and the residual displacement of the intact sandstone block are respectively $0.0302 \mathrm{~mm}, 0.0702 \mathrm{~mm}, 0.0618 \mathrm{~mm}, 0.0983 \mathrm{~mm}, 0.037 \mathrm{~mm}$, the above shows that under low-frequency disturbance, the degree of fragmentation of the block affects the strength of the ultra-low friction effect of the block during the impact. The more the block system rock mass tends to be broken, the greater the horizontal displacement of the block is, the easier it is to cause engineering disasters. As the mining depth increases, the rock blocks tend to be more broken, so stronger support methods should be used in actual projects to increase the strength of the rocks around the roadway to avoid engineering disasters.

(2) Analysis of the influence of the acceleration of broken blocks 


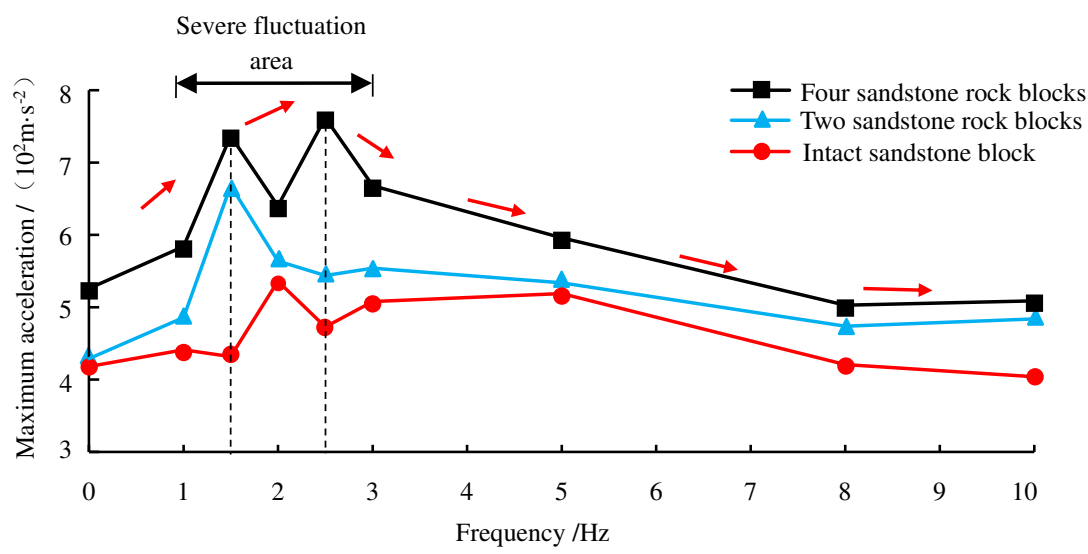

(a) The relationship between the extreme value of the acceleration of the broken block and the disturbance frequency under a horizontal impact of $1.5 \mathrm{MPa}$

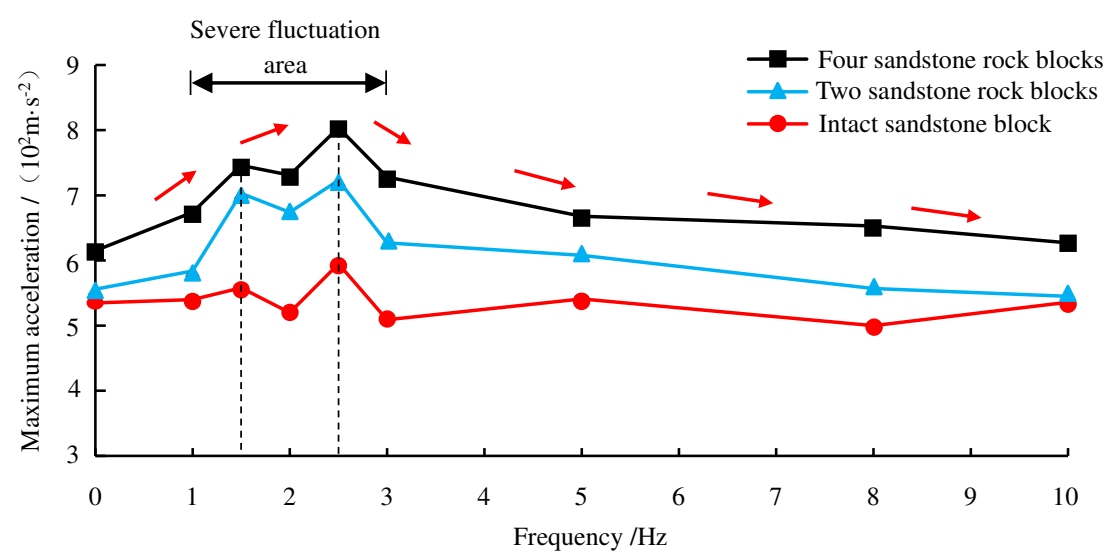

(b) The relationship between the extreme value of the acceleration of the broken block and the disturbance frequency under a horizontal impact of $2.5 \mathrm{MPa}$

Fig. 7 The curve of the maximum acceleration of different broken degree blocks with the change of the disturbance frequency

When the blocks are disturbed by the stress wave, the working block oscillates back and forth in the vertical direction at the equilibrium position. At this time, a horizontal impact is applied, and the acceleration of the working block increases suddenly and is greater than the acceleration without stress wave disturbance. It can be seen from Figure 7 that when the stress wave disturbance frequency is in the range of 1 to $3 \mathrm{~Hz}$, the working block has an obvious ultra-low friction effect under the action of horizontal impact. The greater the horizontal impact energy of the working block is, the greater the extreme value of its acceleration and the stronger the ultra-low friction effect. Under the same level of impact and stress wave frequency, the horizontal displacement of the four sandstone rock blocks is the largest, followed by the two sandstone rock blocks, and the intact sandstone block is the last. With the gradual increase of the disturbance frequency from $3 \mathrm{~Hz}$, the maximum acceleration of the broken block gradually decreases, and gradually returns to the level when there is no disturbance, and the ultra-low friction effect of the broken block is weakened. During the propagation of the stress wave, the accumulated energy of the block increases, and when the block tends to be more broken, the stability of the entire block rock mass decreases during the disturbance process, and the phenomenon of "separation" between the blocks frequently occurs. Therefore, when the block is subjected to strong impact and disturbance, the friction between the blocks is weakened, the acceleration of the block increases, and the strength of the ultra-low friction 
effect increases. The more the block tends to be broken, the greater the amplitude of the block acceleration. Wang Kai-xing et al. (2016) have consistent results.

\subsection{Analysis of the influence of stress wave disturbance intensity}

(1) Analysis of the influence of the horizontal displacement of the broken block

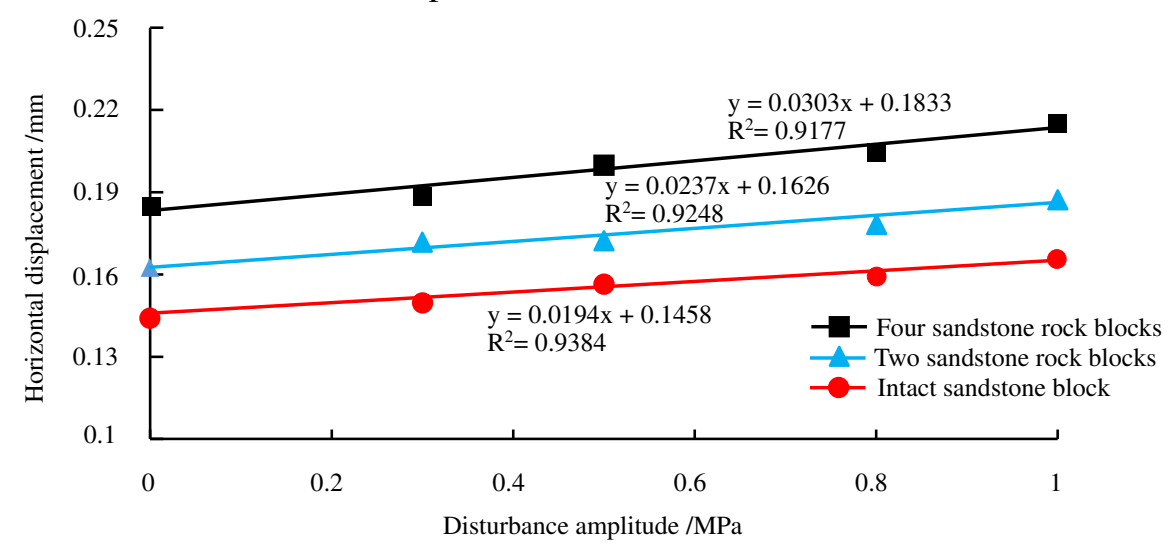

(a) The relationship between the horizontal displacement and the disturbance amplitude under a horizontal impact of $1.5 \mathrm{MPa}$

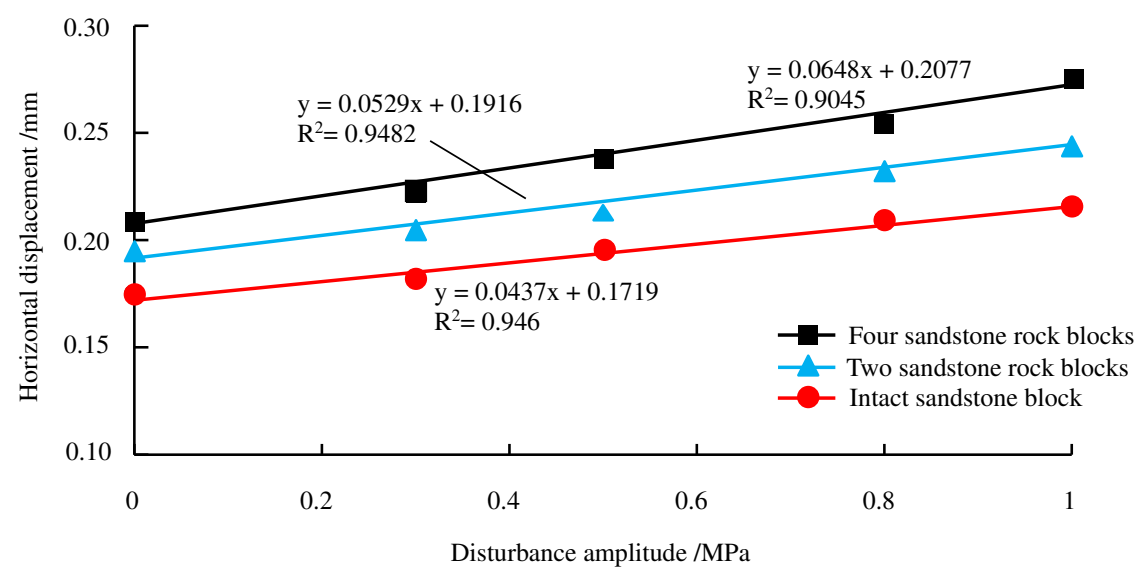

(b) The relationship between the horizontal displacement and the disturbance amplitude under a horizontal impact of $2.5 \mathrm{MPa}$

Fig. 8 The relationship between the horizontal displacement and the disturbance amplitude under different levels of horizontal impact

It can be seen from Figure 8 that with the increase of the disturbance intensity, the horizontal displacement of the working blocks of different fragmentation degrees all increase almost linearly, and the fitting degree is higher. Enhanced ultra-low friction effect. Under the same level of impact and stress wave disturbance intensity, the horizontal displacement of the four sandstone rock blocks is the largest, followed by the two sandstone rock blocks, and the intact sandstone block is the last. When the horizontal impact is $1.5 \mathrm{MPa}$, the horizontal displacement of the four sandstone rock blocks under the disturbance strength of $1 \mathrm{MPa}$ is increased by $16.6 \%$ compared to the horizontal displacement without disturbance, the two sandstone rock blocks is increased by $15.4 \%$, and the intact sandstone block is increased by $15.1 \%$. When the horizontal impact is $2.5 \mathrm{MPa}$, the horizontal displacement of the four sandstone rock blocks under the disturbance strength of $1 \mathrm{MPa}$ is increased by $31.6 \%$ compared to the horizontal displacement without disturbance, the two sandstone rock blocks is increased by $25.6 \%$, and the intact sandstone block is increased by $23 \%$. By comparison, it is found that the increase of the disturbance intensity makes the horizontal displacement of the working block slightly increase, and the increase of the horizontal impact will make this phenomenon obvious. 
(2) Analysis of the influence of the acceleration of broken blocks

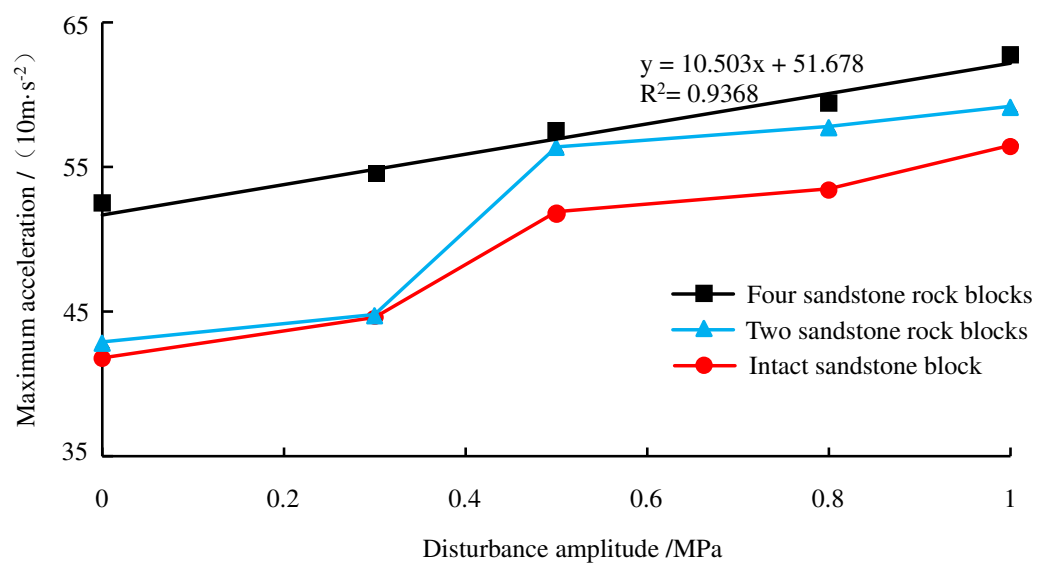

(a) The relationship between the maximum acceleration and the disturbance amplitude under a horizontal impact of 1.5MPa

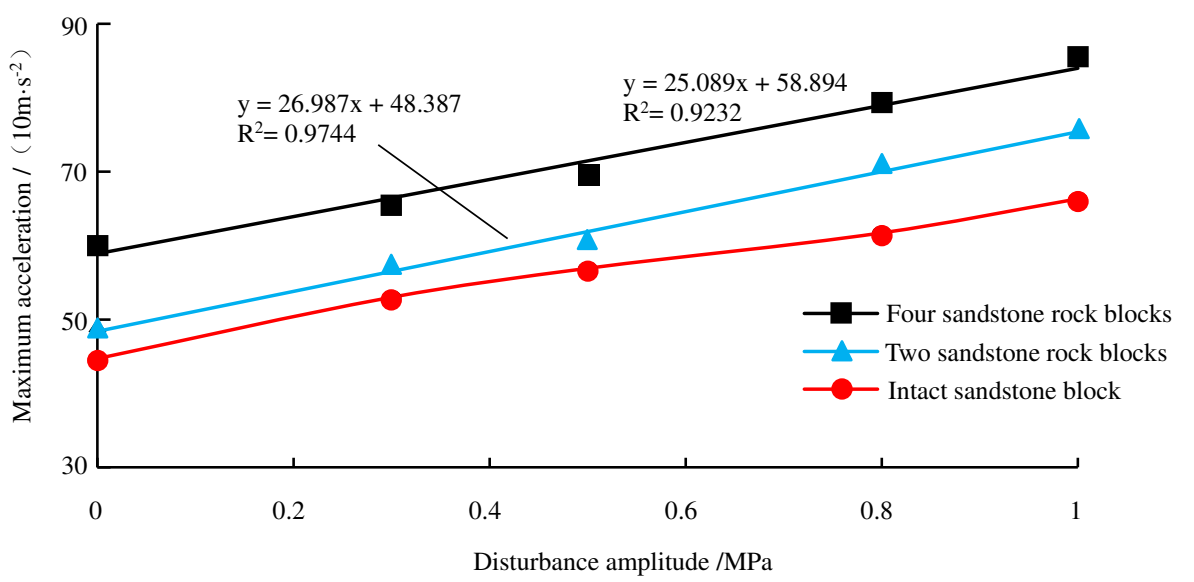

(b) The relationship between the maximum acceleration and the disturbance amplitude under a horizontal impact of $2.5 \mathrm{MPa}$

Fig. 9 The relationship between the maximum acceleration and the disturbance amplitude under different levels of horizontal impact

It can be seen from Fig. 9 that with the increase of the disturbance intensity, the maximum acceleration of the working block of different broken degrees increases to different degrees. Enhanced ultra-low friction effect. Under the same level of impact and stress wave disturbance intensity, the maximum acceleration of the four sandstone rock blocks is the largest, followed by the two sandstone rock blocks, and the intact sandstone block is the last. When the horizontal impact is $1.5 \mathrm{MPa}$, the maximum acceleration of the four sandstone rock blocks under the disturbance strength of $1 \mathrm{MPa}$ is increased by $19.3 \%$ compared to the horizontal displacement without disturbance, the two sandstone rock blocks is increased by $38.1 \%$, and the intact sandstone block is increased by $35 \%$. When the horizontal impact is $2.5 \mathrm{MPa}$, the maximum acceleration of the four sandstone rock blocks under the disturbance strength of $1 \mathrm{MPa}$ is increased by $42.3 \%$ compared to the horizontal displacement without disturbance, the two sandstone rock blocks is increased by $55.8 \%$, and the intact sandstone block is increased by $48.5 \%$. By comparison, it is found that the increase of the disturbance intensity makes the maximum acceleration of the working block increase more obviously, and the increase of the horizontal impact will make this phenomenon more obvious. The more the blocks tend to be broken, when the intensity of the stress wave disturbance increases, the stability of the blocks decreases, and the separation between the blocks is more obvious, so the intensity of the ultra-low friction effect is also greater. 


\subsection{Analysis of the influence of the horizontal displacement difference of the broken block}

Tab 2 Horizontal displacement difference of broken block under different horizontal impact conditions

Horizontal displacement difference

\begin{tabular}{ccc} 
Working block & \multicolumn{2}{c}{$(\mathrm{mm})$} \\
\hline Four sandstone rock blocks & 0.0510 & $2.5 \mathrm{MPa}$ \\
Two sandstone rock blocks & 0.0414 & 0.0582 \\
Intact sandstone block & 0.0302 & 0.0437 \\
\hline
\end{tabular}

The horizontal displacement difference is the difference between the horizontal displacement of the broken rock mass with and without stress wave disturbance. It can be seen from the above table that when the horizontal impact load strength of the working block increases from $1.5 \mathrm{MPa}$ to $2.5 \mathrm{MPa}$, the horizontal displacement difference of the block increases, and the strength of the ultra-low friction effect increases. Under the same level of impact and stress wave disturbance, the horizontal displacement difference of the four sandstone rock blocks is the largest, followed by the two sandstone rock blocks, and the intact sandstone block is the last. Under a horizontal impact of $1.5 \mathrm{MPa}$, the difference in the horizontal displacements of the four sandstone rock blocks and the two sandstone rock blocks are 1.31 times and 1.32 times that of the intact sandstone block, respectively. Under a horizontal impact of $2.5 \mathrm{MPa}$, the difference in the horizontal displacements of the four sandstone rock blocks and the two sandstone rock blocks are 1.35 times and 1.19 times that of the intact sandstone block, respectively. The intensity of the horizontal impact load has little effect on the horizontal displacement difference. This shows that the more rock mass tends to be broken and the roadway damaged by stress is more prone to ultra-low friction effect. This is the same as the actual field observation result. With the increase of mining depth, the rock mass tends to be broken and intermittently formed into a block structure. Under the combined action of ground stress and mining disturbance, the broken block is more prone to dislocation, resulting in ultra-low friction effect. In turn, disasters such as rock bursts occurred.

\section{Research on energy characteristics of ultra-low friction effect}

The occurrence process of rock burst is the instantaneous release of energy (Wang Gui-feng et al. 2018). In the case of dynamic disturbance, according to the research results of Wang Ming-yang et al.(2015), the effect of disturbance makes the rock block vibrate, and the equivalent vibration generated by the disturbed block Kinetic energy $\mathrm{W}$ is:

$$
\mathrm{W}=\frac{1}{2} \mathrm{~m} v^{2}
$$

Where $v$-Equivalent vibration velocity, write formula (5-1) as

$$
\frac{\mathrm{W}}{\mathrm{m}}=\frac{1}{2} v^{2}
$$

Set $\mathrm{W} / m$-Kinetic energy per unit mass.

The horizontal displacement of the working block obtained from the experiment is derived to obtain the block velocity, and then the block kinetic energy per unit mass in the time domain is obtained, and the unit mass kinetic energy is Fourier transformed to obtain its power spectral density curve, which can be known for each frequency The strength of the energy contained.

\subsection{Energy characteristics of ultra-low friction effect of different broken blocks}



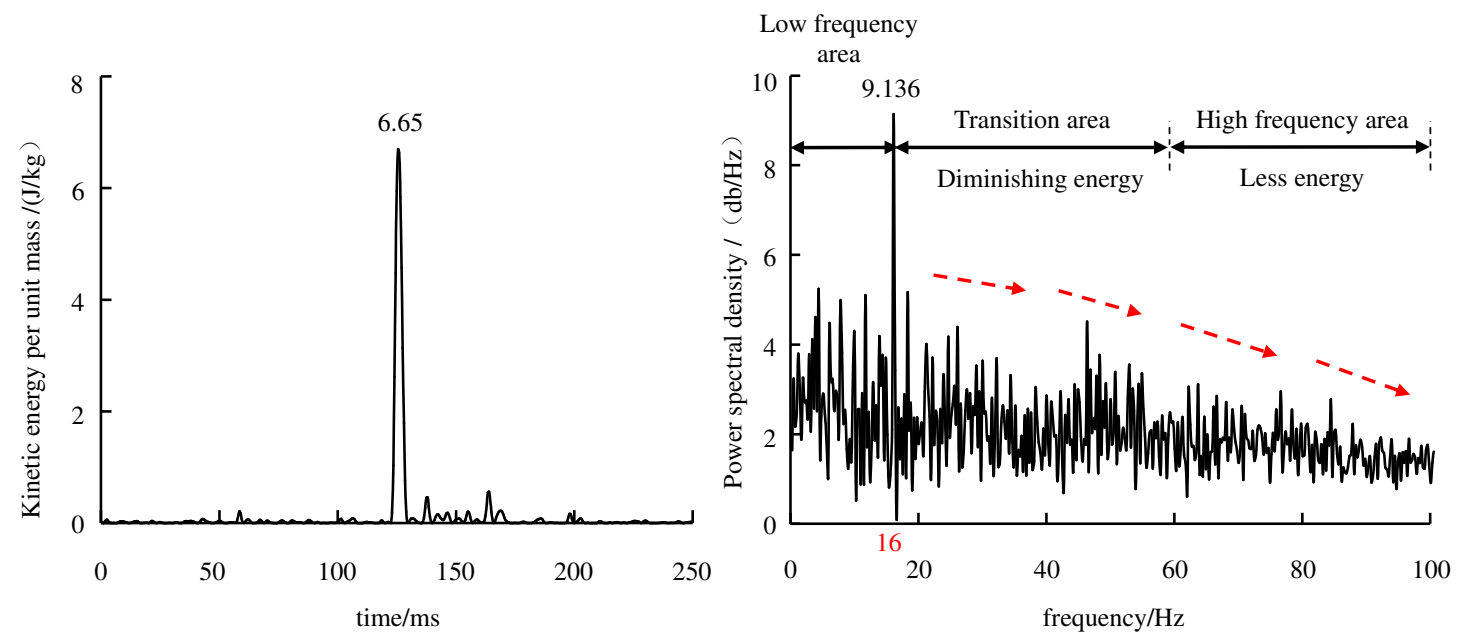

(a) Intact sandstone block
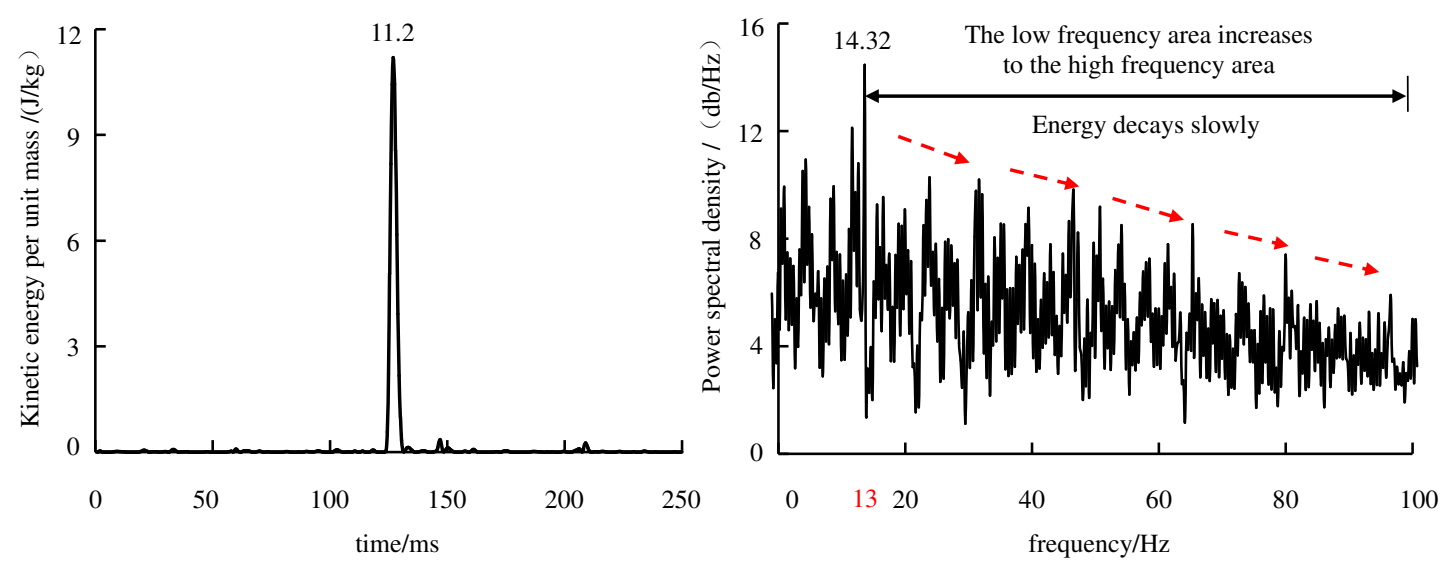

(b) Two sandstone rock blocks
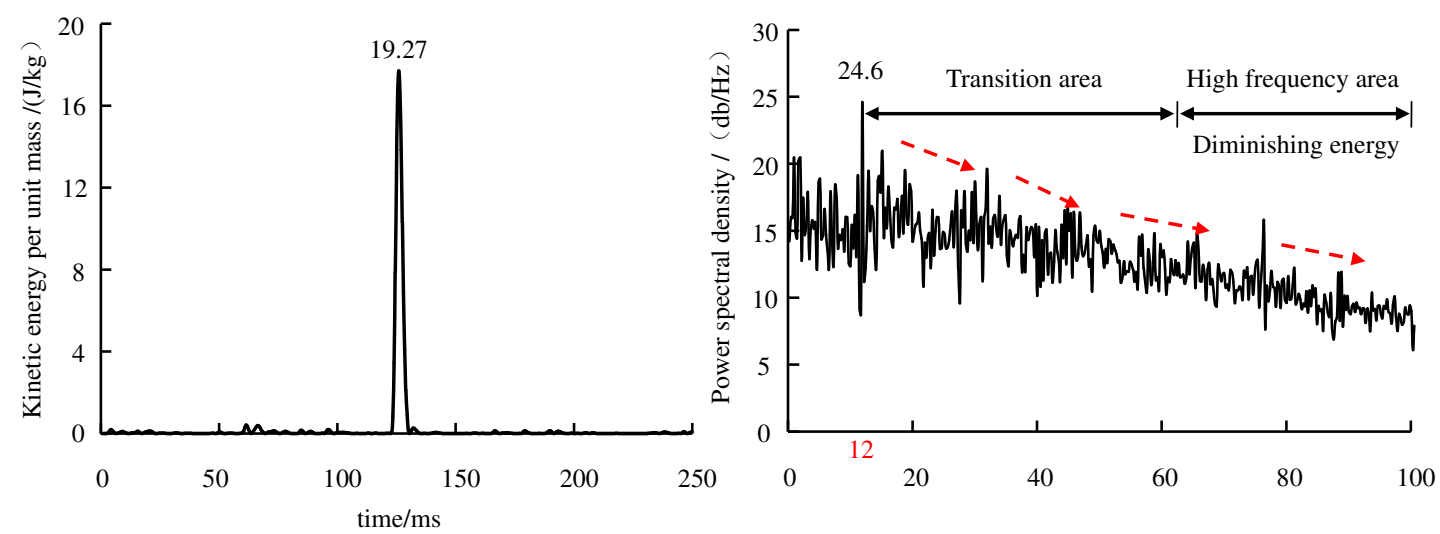

(c) Four sandstone rock blocks

Fig. 10 Kinetic energy per unit mass and power spectral density curves of different fractured degrees under 1.5MPa horizontal impact 

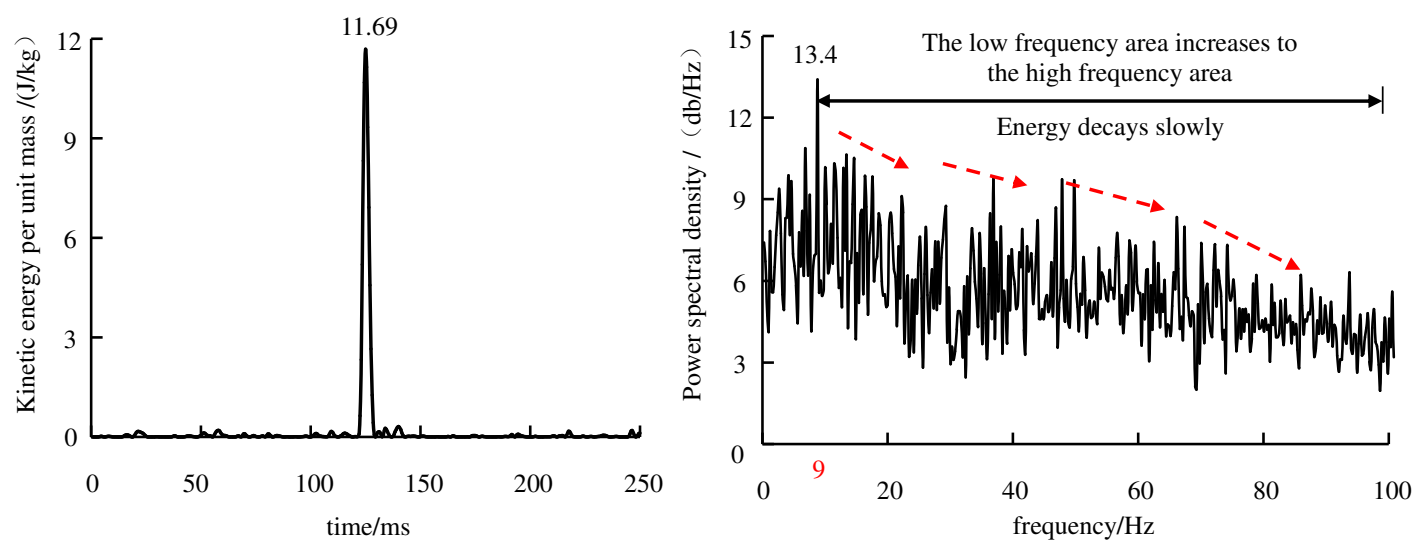

(a) Intact sandstone block
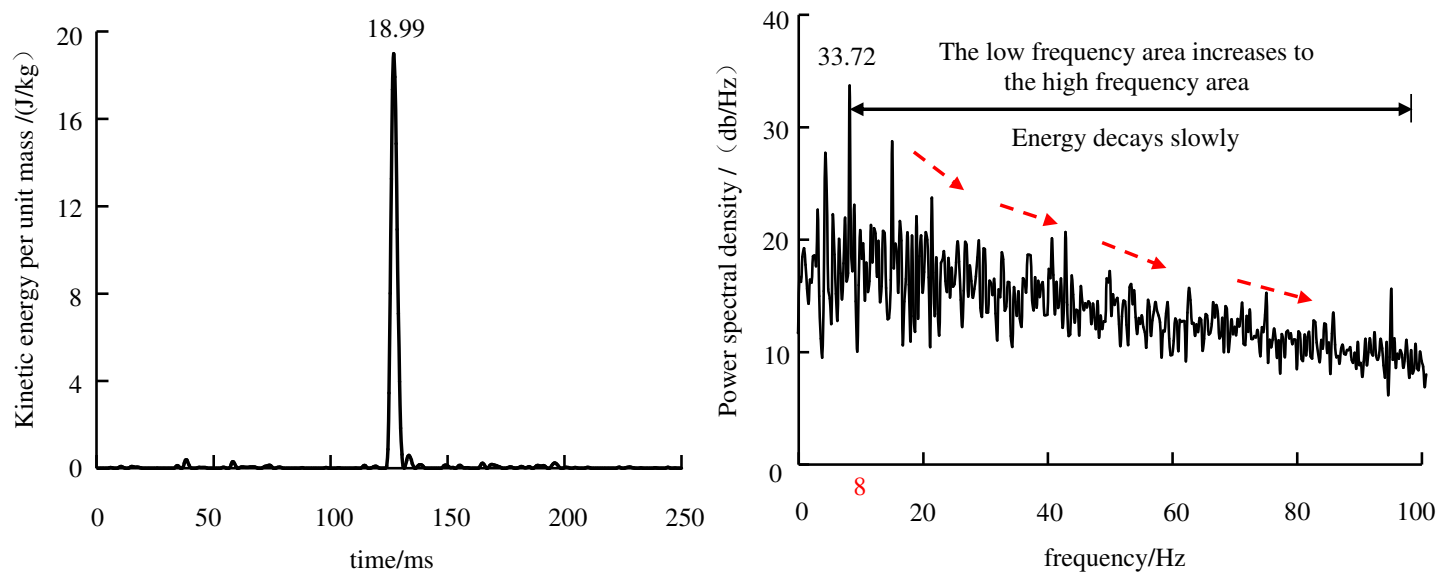

(b) Two sandstone rock blocks
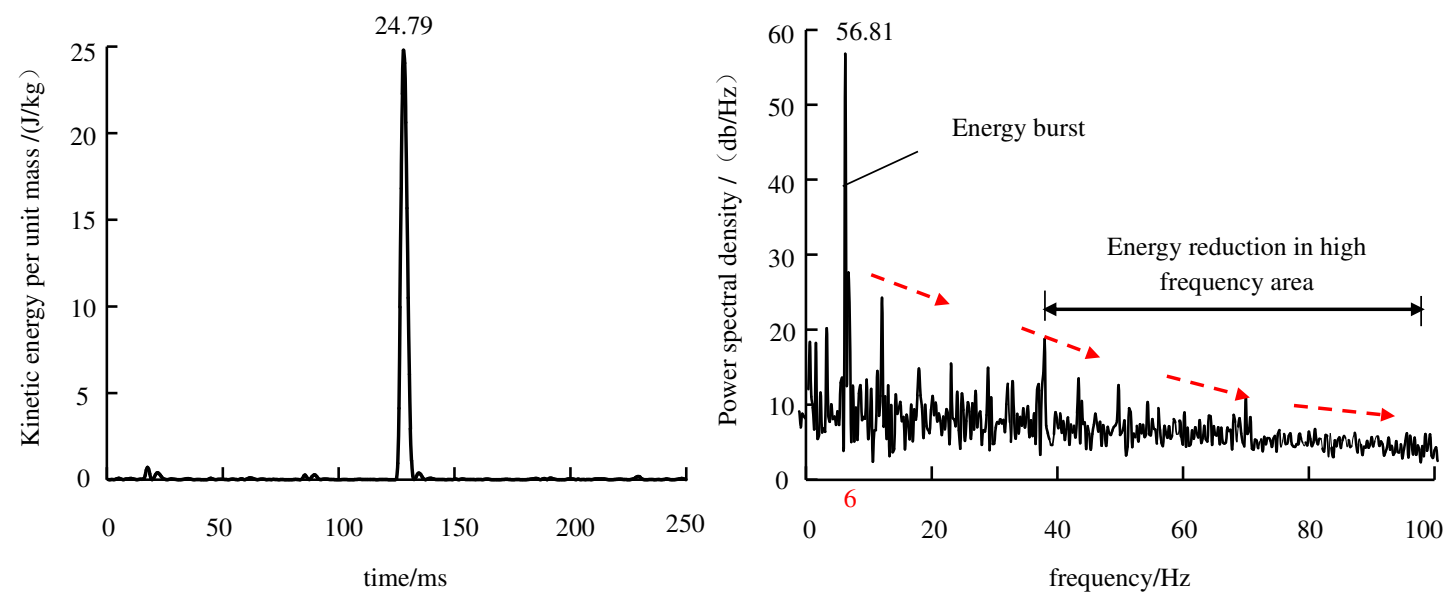

(c) Four sandstone rock blocks

Fig. 11 Kinetic energy per unit mass and power spectral density curves of different fractured degrees

under 2.5MPa horizontal impact

(1) It can be seen from the time domain change curve of unit mass kinetic energy in Figure 10 and Figure 11, Under the horizontal impact of $1.5 \mathrm{MPa}$ and $2.5 \mathrm{MPa}$, the maximum kinetic energy of the working block is reached in $125 \mathrm{~ms}$, that is, when the working block is subjected to horizontal impact for a short time, due to the impact and ultra-low friction effect, the working block's the kinetic energy quickly increases to its maximum value. The smaller the friction between the blocks, the greater the kinetic energy of the working blocks. Due 
to the constraint of axial pressure and the energy consumption of horizontal impact, the energy of the block is greatly attenuated within $4 \mathrm{~ms}$ of impact. After that, the working block returns to a stable vibration state, and the kinetic energy of the block increases with the increase of the horizontal impact load. Therefore, when rock masses with different fracture levels are disturbed by vertical stress waves and have an ultra-low friction effect, their kinetic energy will experience transient accumulation and transient peak effects. Under the same level of impact load, the kinetic energy of the four sandstone rock blocks is the largest, and the kinetic energy of the intact sandstone block is the smallest. At this time, the ultra-low friction effect of the block is the strongest.

(2) The test simulates the occurrence and development process of rock burst well. The study found that the ultra-low friction effect of the broken rock mass is caused by the stress wave disturbance. During this process, the power spectral density amplitude increases instantaneously and fluctuates significantly. The frequency corresponding to the maximum power spectral density of the working block is called the extreme frequency, the more the working block tends to be broken, the closer its extreme frequency is to the low frequency. When ultra-low friction type rock impact occurs, the kinetic energy of the working block has the characteristics of transferring from high frequency to low frequency. The more the working block tends to be broken, the greater the maximum power spectral density. The energy is concentrated in the low frequency area and attenuates in the transition area. The energy value in the high frequency area is small, and it is not easy to produce ultra-low friction effect. When the working block is subjected to a large impact load, the energy increases significantly, and it is easier to produce an ultra-low friction effect under the action of the stress wave.

\subsection{Comparative analysis of related parameters of ultra-low friction effect energy}

Tab 3 The relevant parameters of the ultra-low friction effect of blocks with different degree of fragmentation

\begin{tabular}{ccccccc}
\hline & \multicolumn{2}{c}{ Kinetic energy per unit mass } & \multicolumn{2}{c}{$\begin{array}{c}\text { Extreme frequency } \\
(\mathrm{J} / \mathrm{kg})\end{array}$} & \multicolumn{2}{c}{$\begin{array}{c}\text { Power spectral density } \\
\text { Working block }\end{array}$} \\
& $1.5 \mathrm{MPa}$ & $2.5 \mathrm{MPa}$ & $1.5 \mathrm{MPa}$ & $2.5 \mathrm{MPa}$ & $1.5 \mathrm{MPa}$ & $2.5 \mathrm{MPa}$ \\
\hline Four sandstone rock blocks & 19.27 & 24.79 & 12 & 6 & 24.60 & 56.81 \\
Two sandstone rock blocks & 11.20 & 18.99 & 13 & 8 & 14.32 & 33.72 \\
Intact sandstone block & 6.650 & 11.69 & 16 & 9 & 9.136 & 13.40 \\
\hline
\end{tabular}

(1) Analyzing the data on the kinetic energy per unit mass in Table 3, it is obtained that the kinetic energy of different broken degree blocks increases with the increase of the horizontal impact load, and the energy of the four sandstone rock blocks reaches the maximum during the ultra-low friction effect, intact sandstone block has the least. Under the horizontal impact of $1.5 \mathrm{MPa}$, the energy of the four sandstone rock blocks and the two sandstone rock blocks are respectively 2.90 times and 1.68 times that of the intact sandstone block under the same impact. Under a horizontal impact of $2.5 \mathrm{MPa}$, the energy of the four sandstone rock blocks and the two sandstone rock blocks are respectively 2.12 times and 1.62 times that of the intact sandstone block under the same impact. After blocks of different fracture levels are subjected to horizontal impacts in the stress wave disturbance process, the energy accumulation situation is different. The blocks tend to be broken, the roadways have stress defects, and the rock blocks with lower strength and stability are affected by the impact. The block energy can accumulate to the maximum in a short period of time, and it is very easy to have ultra-low friction effect, which in turn induces natural disasters such as rock impact. Therefore, the degree of rock fragmentation is the main controlling factor that affects the ultra-low friction strength of the block.

(2) Analyzing the data on the extreme frequency in Table 3, it is obtained that the more the block tends to be broken, the lower the dominant frequency when ultra-low friction occurs. The higher the horizontal impact 
load of the block is, the lower the dominant frequency when ultra-low friction occurs. When the horizontal impact is $1.5 \mathrm{MPa}$, the main frequency of the block is within $20 \mathrm{~Hz}$, and when the horizontal impact is 2.5 $\mathrm{MPa}$, the main frequency of the block is within $10 \mathrm{~Hz}$. This is consistent with the conclusion that the actual underground ultra-low friction effect occurs in the low frequency range.

(3) Analyzing the data on the power spectrum density in Table 3, it is obtained that the more the block tends to be broken, the higher the power spectrum density is when the ultra-low friction occurs. The higher the horizontal impact load of the block is, the higher the power spectral density when ultra-low friction occurs. The more the block tends to be broken, the stronger it is subjected to horizontal impact, the more obvious the dynamic response, and the more prone to ultra-low friction effect, which will cause rock burst disasters.

\section{Discussion}

With the gradual reduction and depletion of shallow resources, mines in various countries around the world have entered deep mining (Zhao An-ping et al.2018; Pathegama G. Ranjith et al.2017; L Chen et al.2020 ). Deep mining is the subject and inevitable trend of mining activities in the world in the future. Therefore, this article uses independent development of ultra-low friction test equipment to differentiate The degree of fragmentation of the rock block is the research object, and the confining pressure of axial compression is used to simulate the stress state of the deep rock formation. The vertical and horizontal impacts are used to simulate blasting, rock transportation, mechanical operation and other activities. The conclusions obtained in this paper are compared with previous studies and found that the experimental research of Su Guo-shao et al. (2016) found that in the frequency range of $0 \sim 3 \mathrm{~Hz}$, as the frequency of axial disturbance load increases, the kinetic energy of rock burst ejection first increases and then decreases. Pan Yi-shan (2014) and other studies found that the frequency of external disturbances will change the maximum stretch value between rock blocks. When the disturbance frequency is close to the quasi-resonant frequency of the block system rock mass, the maximum stretch value increases sharply. Compared with the above experiments, due to differences in loading conditions, physical and mechanical properties and dimensions of the specimens, this paper finds that ultra-low friction is prone to occur when the perturbation frequency is $1 \sim 3 \mathrm{~Hz}$. Limited to the only research object, the conclusions of this article have yet to be verified by a large number of experiments. In the future, ultra-low friction tests under field conditions will be carried out to make theoretical and practical application values for the prediction and prevention of deep rock bursts.

\section{Conclusion}

(1) The stress wave disturbance frequency has a wave effect on the ultra-low friction effect of broken rock mass. The stress wave disturbance frequency is in the range of $1 \sim 3 \mathrm{~Hz}$. The horizontal displacement and acceleration maximum value of the block subjected to dynamic response increase significantly, and the ultra-low friction effect is the strongest. As the disturbance frequency of the stress wave increases again, the maximum horizontal displacement and acceleration of the block gradually fall back to the state without disturbance. The more broken the block, the greater the dynamic response.

(2) The influence of the intensity of the stress wave disturbance on the ultra-low friction effect of the crushed block changes linearly. The more the block is broken, the greater the intensity of the stress wave disturbance is, and the more obvious the ultra-low friction effect of the block is.

(3) Under the same level of impact, the ultra-low friction effect of the block is four combined blocks, two combined blocks and complete sandstone blocks in order from strong to weak. The horizontal impact load strength is also an important factor for the enhancement of the ultra-low friction effect of the block. 
(4) Under the combined action of axial compression, horizontal impact, and stress wave disturbance, the kinetic energy of the block has the characteristics of agglomeration and short-term peak value. When the strength of the ultra-low friction effect is the largest, it is manifested in the block unit mass kinetic energy, power spectral density, and kinetic energy extreme value The frequency shifts from high frequency to low frequency, and the waveform tends to be low frequency waves, and the main frequency of the block has an ultra-low friction effect within $20 \mathrm{~Hz}$.

Acknowledgments: This research was financially supported by the National Science Foundation of China (51974148) and Liaoning Xingliao Talent Program (XLYC1807130).

Ethical statements: I certify that this manuscript is original and has not been published and will not be submitted elsewhere for publication while being considered by International Journal of Coal Science \& Technology. And the study is not split up into several parts to increase the quantity of submissions and submitted to various journals or to one journal over time. No data have been fabricated or manipulated (including images) to support our conclusions. No data, text, or theories by others are presented as if they were our own.

The submission has been received explicitly from all co-authors. And authors whose names appear on the submission have contributed sufficiently to the scientific work and therefore share collective responsibility and accountability for the results.

Conflict of Interest: The authors declare that they have no conflict of interest. This article does not contain any studies with human participants or animals performed by any of the authors. Informed consent was obtained from all individual participants included in the study.

\section{References}

Kurlenya M V, Oparin V N, Vostrikov V I, et al (1999) Effect of anomalously low friction in block media[J]. Journal of Applied Mechanics and Technical Physics, 40(6): 1116-1120

Oparin V N, Balmashnova E G, Vostrikov V I, et al (2001) On Dynamic Behavior of "Self-Stressed/" Block Media. Part II: Comparison of Theoretical and Experimental Data[J]. Journal of Mining Science, 37(5): 455-461.

Kurlenya M V, Oparin V N, Vostrikov V I, et al (1996) Pendulum-type waves. Part II: Experimental methods and main results of physical modeling[J]. Journal of Mining Science, 32(4): 245-273.

B.G. Tarasov,M.F. Randolph (2007) Frictionless shear at great depth and other paradoxes of hard rocks[J]. International Journal of Rock Mechanics and Mining Sciences, 45(3):316-328

QIAN Qi-hu (2004) The key problems in deep underground space development [R] .In: The 230th Xiangshan Academic Conference: Basic Crucial Problems in Deep Underground Space Development, Beijing, ( in Chinese) .

CUI Yong-quan, MA Sheng-li, LIU Li-qiang (2005) Effect of lateral stress perturbation on frictional behavior: an experimental study[J]. Seismology and Geology, 27(4): 645-652. (in Chinese).

Wang Hong-liang, Zhou Ze-ping, Wang Ming-yang (2006) Study on dynamic performance of object interface [J]. Protective engineering, 28 (2): 30-35. (in Chinese).

Wang Hong-liang, Ge Tao, Wang De-rong, et al (2007) Comparative analysis of dynamic characteristics of block rock mass by theory and experiment [J]. Journal of rock mechanics and engineering, 26 (5): 951-958. (in Chinese). 
Wu Hao, Fang Qin, Wang Hong-liang (2008) Mechanism analysis of ultra-low friction in deep block rock mass [J]. Acta geotechnical engineering, 30 (5): 769-775. (in Chinese).

Hao WU, Qin FANG, Ya-dong ZHANG, et al (2009) Mechanism of anomalous low friction phenomenon in deep block rock mass [J]. Mining Science and Technology (China), 19(4):409-419.

Hao Wu, Qin Fang, Yu-sheng Lu, et al (2009) Model tests on anomalous low friction and pendulum-type wave phenomena [J]. Progress in Natural Science, 19(12):1805-1820

Wu Hao, Fang Qin, Zhang Ya-dong, et al (2010) Experimental and theoretical study on wave characteristics of one-dimensional block geological blocks [J]. Acta geotechnical engineering, 32 (4): 600-611. (in Chinese).

Xu qiong-ping, Lu Yu-sheng, Wang De-rong (2009) Experiment on friction weakening effect of deep rock mass system [J]. Journal of PLA University of science and Technology (NATURAL SCIENCE EDITION), 10 (3): 285-289. (in Chinese).

Wang Kai-xing, pan Yi-shan, Dou Li-ming (2016) Study on energy transfer law of block rock mass during pendulum wave propagation [J]. Journal of geotechnical engineering, 38 (12): 2309-2314. (in Chinese).

Liu Dong-qiao, Zhang Xiao-yun, he Man-Chao, Wang Jiong, Wang Yang (2018) Experimental detritus study of sandstone rock burst [J]. Journal of mining science, 3 (3): 246:252. (in Chinese).

Li Li-ping, Li Wei-jun, pan Yi-shan (2019) Impact analysis of impact disturbance on ultra-low friction rock burst [J]. 38 (1): 111-120. (in Chinese).

Lv Jia-qing (2015) FLAC3D numerical simulation study on ultra-low friction effect of deep rock mass [D] Liaoning Technical University, (in Chinese).

Li Jie, Wang Ming-yang, Jiang Hai-ming, Deng Shu-xin and Li Xin-ping (2018) Nonlinear rock mechanics in explosion and impact (II): physical simulation test of rock block sliding induced by impact disturbance [J]. Journal of rock mechanics and engineering, 37 (2): 291-301. (in Chinese).

Jiang Hai-ming, Li Jie, Wang Ming-yang (2019) Theoretical and experimental study on low friction effect in sliding instability of block rock mass [J]. Geotechnical mechanics, 40 (4): 1-8. (in Chinese).

Zhao An-ping, Feng Chun, Guo ru-kun, Li Shi-hai, Jia Jian-jun (2018) Influence of joint characteristics on stress wave propagation and blasting effect [J]. Journal of rock mechanics and engineering, 37 (09): 2027-2036. (in Chinese).

Pathegama G. Ranjith, Jian Zhao, Minghe Ju, Radhika V.S. De Silva, Tharaka D. Rathnaweera, Adheesha K.M.S. Bandara (2017) Opportunities and Challenges in Deep Mining: A Brief Review [J] Engineering Volume 3, Issue 4. PP 546-551.

L Chen, Chen L, Wu S, Guo L J (2020) Study on the integrated planning of deep mining considering rock burst prediction [J]. IOP Conference Series: Earth and Environmental Science Volume 570, Issue 4, PP 042-047.

Wang Gui-feng, Dou li-ming, Cai Wu, et al (2018) Study on triggering mechanism of unstable energy of rock burst [J]. Journal of China University of mining and technology, 47 (01): 190-196. (in Chinese).

Wang Ming-yang, Li Jie, Li Kai-rui (2015) Principle and application of energy action in nonlinear mechanics of deep rock mass [J]. Journal of rock mechanics and engineering, 34 (4): 659-667. (in Chinese).

Su Guo-Shao, Hu Li-hua, Feng Xia-Ting, et al (2016) True triaxial experimental study of rock burst process under low frequency cyclic disturbance load combined with static load [J]. Chinese Journal of Rock Mechanics and Engineering, 35 (7): 1309-1322. (in Chinese).

PAN Yi-shan, WANG Kai-xing (2014) Pendulum-type waves theory on the mechanism of anomalously low friction between rock masses [J]. Seismology and Geology, 36(3): 833-844. (in Chinese). 
